\title{
Home use of margarine is an important determinant of plasma trans fatty acid status: a biomarker study
}

\author{
C. Murray Skeaff* and Sonya Gowans \\ Department of Human Nutrition, University of Otago, Dunedin, New Zealand
}

(Received 22 July 2005 - Revised 16 December 2005 - Accepted 6 January 2006)

\begin{abstract}
The contribution of the home use of margarines, made with partially hydrogenated vegetables oils, to total trans fatty acid intake is difficult to determine using dietary assessment because food composition databases are incomplete for trans fatty acids; moreover, hidden fats in manufactured foods may be the predominant sources of trans fatty acids. The objective of our study was to determine, using plasma phospholipid trans fatty acid composition as a surrogate measure of exposure, whether the home use of margarine or butter is an important determinant of trans fatty acid status. We conducted a community-based (Dunedin, New Zealand), cross-sectional survey of people who consumed either margarine ( $n$ 65) or butter $(n$ 64) but not both for home use. The levels of the 18:1 trans isomers commonly found in partially hydrogenated vegetable oils were all significantly higher in the plasma phospholipids of margarine compared with butter consumers, with the exception of $18: 1 n-7 \mathrm{t}$, which did not differ. Among margarine consumers, the percentage of total fat from margarine was significantly correlated with levels of phospholipid $18: 1 n$-6t, $18: 1 n-8 \mathrm{t}$ and $18: 1 n-12 / 9 \mathrm{t}$ isomers $(r 0.57-0.63, P<0.001)$ but only weakly with $18: 1 n-7 \mathrm{t}(r 0 \cdot 30, P=0 \cdot 016)$. The intake of fat from fast foods, bakery products or meat and meat products was not associated with plasma phospholipid trans isomeric composition. The home use of margarine, made with partially hydrogenated vegetable oils, is an important determinant of trans fatty acid exposure in New Zealand.
\end{abstract}

Trans fatty acids: Dietary fats: Margarine: Plasma phospholipids: Biological marker

A high intake of trans fatty acids from partially hydrogenated plant oils has been associated with an increased risk of cardiovascular morbidity and mortality (Ascherio et al. 1996; Hu et al. 1997; Pietinen et al. 1997). The association is biologically plausible because trans unsaturated fatty acids increase plasma total and LDL-cholesterol and decrease HDL-lipoprotein cholesterol concentrations in comparison with cis unsaturated fatty acids (Mensink \& Katan, 1990; Lichtenstein et al. 1999).

Dietary sources of trans fatty acids are foods containing ruminant fat and partially hydrogenated vegetable or fish oils. The trans fatty acid content of foods containing partially hydrogenated oils tends to be higher than in ruminant fats, although levels in the former vary considerably (Firestone \& Sheppard, 1992). The two sources also differ in positional isomer composition: trans fatty acids from ruminant fats are characterised by the predominance of trans vaccenic acid (C18:1n-7t; Parodi, 1976; Precht \& Molkentin, 1995; Wolff, 1995), whereas 18:1n-9t, 18:1n-8t and $18: 1 n-7 \mathrm{t}$ are the major trans isomers in partially hydrogenated oils (Marchand, 1982; Slover et al. 1985; Molkentin \& Precht, 1996).

Assessing individual intakes of trans fatty acids by traditional methods of dietary assessment is not possible in most countries because few national food composition databases include a full dataset of the trans fatty acid content of foods. Even if the relevant database included trans fatty acids, obtaining accurate estimates of intake would be difficult because the food that an individual consumes may not have been prepared with the same type of fat as the matching food in the database. This 'hidden' fat is derived predominantly from manufactured foods and foods prepared outside the home (Elias \& Innis, 2002), it represents a substantial proportion of total fat intake and its contribution to trans fatty acid intake is difficult to estimate (Innis et al. 1999). The other major food source of trans fatty acids in the diet is the home consumption of margarine, made with partially hydrogenated plant oils, or butter. To what extent this choice, in the context of unknown and potentially much larger amounts of trans fat from manufactured foods, affects trans fatty acid exposure is not known.

Biological markers of fat intake offer an alternative to assessing trans fatty acid exposure because tissue fatty acid composition reflects actual rather than reported intake, thus avoiding the particular problems of quantifying 'hidden' fats or the well-established underreporting of fat intake (Beaton et al. 1979; Bingham, 1987; Bingham et al. 1994). Biomarkers of trans fatty acid intake are particularly good (Seppanen-Laakso et al. 1996; Vidgren et al. 1998; Lichtenstein et al. 2003) because there is negligible endogenous synthesis of trans fatty acids.

In our study, we compared the trans fatty acid composition of plasma phospholipid in people who used either butter or partially hydrogenated table spreads, but not both, to examine the extent to which this food choice is a determinant of total trans fatty acid exposure. 


\section{Methods}

Participants were recruited from the Dunedin community by advertisements in local newspapers and posters around the city. Inclusion criteria for the study were: 18 years of age or older, and a user of either butter or margarine - but not both - as a spread. The type of fat used in cooking or baking was not a criterion for selection. For the sake of simplicity, vegetable oil-based margarines and table spreads are referred to as margarines throughout the manuscript. The study was outlined to the participants, both verbally and via a written information sheet, and signed informed consent was obtained. The Human Ethics Committee of the University of Otago approved the study protocol.

Single measurements of weight (SECA digital scales; SECA, Hamburg, Germany) and height (custom made stadiometer) were taken at the Human Nutrition Department Research Clinic. Medication use was self-reported. Volunteers were excluded from participation if they were using medications known to affect blood lipids. Smoking status was ascertained by questionnaire.

Participants completed a weighed and estimated $4 \mathrm{~d}$ diet record, encompassing three weekdays and one weekend day, over a 1 week period. Group instruction sessions on keeping a diet record were given. The energy and nutrient composition of the diets was calculated with reference to the New Zealand Food Composition (Burlingame et al. 1993). The likelihood that reported dietary intake represented actual intake was determined using the cut-offs developed by Goldberg et al. (1991). Participants with a ratio of energy intake:BMR of less than 0.88 were excluded from the analysis.

A blood sample drawn from an arm vein was collected from participants who had fasted for $10-12 \mathrm{~h}$ overnight. All samples were obtained no later than 1 week after completing the diet record. Blood was collected into a Vacutainer (Becton, Dickenson and Company, Franklin Lakes, NJ, USA) with EDTA as anticoagulant, stored on ice and centrifuged within $2 \mathrm{~h}$ at $2500 \mathrm{~g}$ for $15 \mathrm{~min}$ at $-4^{\circ} \mathrm{C}$. Plasma was removed, and several aliquots were stored at $-80^{\circ} \mathrm{C}$.

An internal standard, di-heptadecanoylphosphatidylcholine (C17:0 PC; Sigma, St Louis, MO, USA) was added to plasma samples prior to lipid extraction. Lipids from $1 \mathrm{ml}$ plasma were extracted, the phospholipids separated and fatty acid methyl esters prepared as previously described (Holub \& Skeaff, 1987). A sample of water, as a blank, was extracted with every eight plasma samples.

Fatty acid methyl esters were auto-injected and separated using a BPX-70 capillary column, $100 \mathrm{~m} \times 0.22 \mathrm{~mm}$ internal diameter, $0.25 \mu \mathrm{m}$ film (SGE, Melbourne, Australia) on a HP6890 gas chromatograph (Agilent, Avondale, PA, USA). The oven was held at an initial temperature of $165^{\circ} \mathrm{C}$ for $52 \mathrm{~min}$, then increased at a rate of $5^{\circ} \mathrm{C} / \mathrm{min}$ to a final temperature of $210^{\circ} \mathrm{C}$, which was held for $59 \mathrm{~min}$. Total run time was $120 \mathrm{~min}$. Both the injector and the flame ionisation detector ports were at $250^{\circ} \mathrm{C}$. Carrier gas flow (He) was maintained at $1.0 \mathrm{ml} / \mathrm{min}$ (linear gas velocity $20 \mathrm{~cm} / \mathrm{s}$ ) throughout the temperature programme, with an inlet split ratio of $30: 1$.

A composite standard made from commercially available methyl esters (NuCheck Prep, Elysian, MN, USA; Sigma) was run every eight samples to ensure a correct estimation of retention times. The $18: 1$ and $18: 2$ positional and geometrical isomers were identified by retention time matching with commercial standards, and comparison with published separations on similar highly polar cyanopropyl polysiloxane stationary phases (Ratnayake \& Beare-Rogers, 1990; Hudgins et al. 1991; Ratnayake \& Pelletier, 1992; Wolff, 1995; Molkentin \& Precht, 1996). The $n$-12 to $n-9$ trans isomers of $\mathrm{C} 18: 1$ co-eluted and are described in the paper as $18: 1 n-12 / 9 t$. The position of the double bonds in the $18: 2$ cis/trans isomers was not established, and these isomers are arbitrarily identified by sequential number.

To estimate the precision of the analytical method, one pooled plasma sample was analysed for every eight study samples. The $\mathrm{CV}$ for the major phospholipid fatty acids contributing more than $5 \mathrm{~mol} \%$ ranged from $1.0 \%$ to $3.6 \%$, whereas for fatty acids contributing $1-5 \mathrm{~mol} \%$, the $\mathrm{CV}$ ranged from $1.2 \%$ to $6.3 \%$. The $\mathrm{CV}$ for the $18: 1$ trans positional isomers $n$-12/9t, $n$-8t, $n$-7t and $n$-6t were 5.6, 9.0, $1 \cdot 3$ and $2 \cdot 3$, respectively.

Statistical analyses were performed using SPSS v.4.0 for the Macintosh (SPSS Inc, Chicago, IL, USA). Multiple regression, with adjustment for sex, age and BMI where appropriate, was used to estimate the mean difference $(95 \% \mathrm{CI})$ in dietary constituents or plasma fatty acids. When necessary, variables were log-transformed to improve the normality and/or equality of variance prior to analysis. Pearson correlation coefficients were calculated to assess the relationship between dietary intake and plasma phospholipid fatty acid composition. Correlations were performed within the butter and margarine users separately because an analysis including all participants tended to cluster butter users around the zero margarine intake and margarine users around the zero butter intake. The resultant highly skewed distributions were not appropriate for correlation analysis.

The study sample size was calculated to detect a minimum difference between butter and table spread consumers of $0 \cdot 01$ weight $\%$ in total trans isomers in human plasma phospholipids; the assumed population standard deviation was 0.02 (van de Vijver et al. 1996). Sixty-three participants were needed in each group to detect a difference greater than or equal to 0.01 weight $\%$ with $80 \%$ power and an $\alpha$ level of 0.05. Recruitment took place during April and May of 1996, and by mid June 133 participants (sixty-six butter and sixtyseven margarine users) had completed the study.

\section{Results}

Four participants (two butter and two margarine users) reported energy intakes less than $88 \%$ of their BMR and were excluded because they were considered to have underreported their food intake; data from 129 participants were included in the analyses.

Margarine users were, on average, 5 years older, $2.3 \mathrm{~kg}$ heavier and $1.2 \mathrm{~cm}$ shorter, and had a higher BMI $\left(1.1 \mathrm{~kg} / \mathrm{m}^{2}\right)$, than those who used butter (Table 1). There were more men and fewer women in the margarine group. The mean BMI of male and female participants was $26 \cdot 1 \mathrm{~kg} / \mathrm{m}^{2}$ (n 58) and $25.6 \mathrm{~kg} / \mathrm{m}^{2}$ ( $\left.n 71\right)$, respectively.

Butter users consumed more butter per d ( $32 \mathrm{~g})$ as a spread or in baking and cooking than margarine users did table spread ( $20 \mathrm{~g}$; Table 2). The energy intake of butter users was $12 \%$ higher $(P=0.002)$ than the intake of margarine users. Protein 
Table 1. Participant characteristics

(Mean values and standard deviations)

\begin{tabular}{lccccc}
\hline & \multicolumn{2}{c}{$\begin{array}{c}\text { Margarine } \\
(n \text { 65) }\end{array}$} & & \multicolumn{2}{c}{$\begin{array}{c}\text { Butter } \\
(n \text { 64) }\end{array}$} \\
\cline { 2 - 3 } \cline { 5 - 6 } Characteristic & Mean & SD & & Mean & SD \\
\hline Women $(n)$ & 33 & & & 38 & \\
Men $(n)$ & 32 & & & 26 & \\
Smokers $(n)$ & 3 & & & 6 & \\
Age (years) & 51 & 16 & & 46 & 18 \\
Weight $(\mathrm{kg})$ & 74.7 & 15.8 & & 72.4 & 18.1 \\
Height $(\mathrm{cm})$ & 168.0 & 8.1 & & 169.2 & 8.9 \\
BMI $\left(\mathrm{kg} / \mathrm{m}^{2}\right)$ & 26.4 & 4.8 & & 25.3 & 6.5 \\
\hline
\end{tabular}

For details of subjects and procedures, see p. 378 of proofs.

provided $15 \%$ energy in both butter and margarine users; however, butter users obtained less energy from carbohydrate $(4 \% \mathrm{~kJ}, P=0 \cdot 001)$ and more from total fat $(4 \% \mathrm{~kJ}, P<0 \cdot 001)$. Saturated fat intake was higher $(6 \% \mathrm{~kJ}, P<0.0001)$ in butter users, whereas that of polyunsaturated fat was lower $(2 \% \mathrm{~kJ}$, $P<0.001)$ than in participants who used margarine. Monounsaturated fat intake contributed an equivalent percentage energy (11) in butter and margarine users. Similar differences were seen when dietary fat was expressed as a percentage of total fat intake. Accordingly, the dietary polyunsaturated: saturated fat ratio of butter users was less than half the ratio of the diets of margarine users $(0.2 v .0 .5, P<0.001)$. The amount or proportion of dietary fat from all the food groups except dairy products (including butter) - higher in butter consumers - and fats and oils (includes margarine) - higher in margarine consumers - was similar in butter and margarine users (Table 3).

The mean proportion of total fatty acids as 14:0 and 15:0 in the plasma phospholipids of butter users was significantly higher $(P \leq 0.001)$ than that in margarine users (Table 4).
There was no difference in 16:0; however, butter users showed a lower 18:0 level $(P=0 \cdot 029)$. Levels of the MUFA $16: 1 n-7$ and $18: 1 n-9$ were significantly lower in the plasma phospholipid of margarine consumers $(P \leq 0 \cdot 027)$. Plasma phospholipid linoleate $(18: 2 n-6)$ and arachidonate $(20: 4 n-6)$ concentrations were higher in margarine than butter consumers $(P \leq 0 \cdot 001)$ whereas those of the $n-3$ PUFA $18: 3 n-3$, $20: 4 n-3,20: 5 n-3$ and $22: 5 n-3$ were lower.

Plasma phospholipid 15:0 and 14:0 composition was significantly correlated with dairy fat as well as saturated fat intake (Table 5) but not with ruminant meat fat $(r-0 \cdot 11$, $P=0 \cdot 117)$. The 15:0 correlations were strongest when fat intake - for example, saturated fat - was expressed as a percentage of total fat $(r 0.59, P<0.001)$ or of total energy $(r 0.55, P<0.001)$ rather than in $\mathrm{g} / \mathrm{d}(r 0.42, P<0.001)$. The same was true for 14:0. The correlation coefficients were identical whether plasma phospholipid fatty acid composition was expressed as weight $\%$ or mol $\%$.

Significant differences in the trans isomer composition of plasma phospholipids were detected between butter and margarine consumers (Table 6). Only an aggregate mol \% composition of the 18:1 trans positional isomers with the double bond located at the $n-12, n-11, \mathrm{n}-10$ and $n-9$ positions $(18: 1 n-12 / 9 t)$ could be obtained as these isomers co-eluted. Trans vaccenic acid $(18: 1 n-7 \mathrm{t})$ comprised an equivalent proportion of plasma phospholipid fatty acids in both butter and margarine users $(0.46 \mathrm{~mol} \%)$, whereas all the other $18: 1$ trans positional isomers - $18: 1 n-12 / n-9 \mathrm{t}, 18: 1 n-8 \mathrm{t}$ and $18: 1 n-6 \mathrm{t}$ - were higher in the plasma phospholipids of margarine compared with butter users $(P<0.001)$. Consequently, the total 18:1 trans fatty acid content was $0.306 \mathrm{~mol} \%$ $(P<0 \cdot 001)$ higher in margarine than butter users.

$18: 1$ trans isomers accounted for $68 \%$ and $74 \%$ of the total trans fatty acid content of phospholipids in butter and margarine users, respectively. Trans vaccenic acid (18:1n-7t) was the

Table 2. Energy and nutrient composition of diets (Mean values and standard deviations)

\begin{tabular}{|c|c|c|c|c|c|c|}
\hline \multirow[b]{2}{*}{ Diet component } & \multicolumn{2}{|c|}{ Margarine (n 65) } & \multicolumn{2}{|c|}{ Butter (n 64) } & \multicolumn{2}{|c|}{ Difference† } \\
\hline & Mean & SD & Mean & SD & Mean & $95 \% \mathrm{Cl}$ \\
\hline & & & 10 & & & \\
\hline Energy (kJ) & 9227 & 2008 & 486 & 2862 & $1110^{*}$ & 425,1796 \\
\hline Protein (\%kJ) & 15 & 3 & 15 & 2 & 0 & $-1,1$ \\
\hline Carbohydrate (\%kJ) & 50 & 7 & 46 & 6 & $-4^{*}$ & $-6,-2$ \\
\hline Total Fat (\%kJ) & 32 & 5 & 36 & 6 & $4^{*}$ & 2,7 \\
\hline SAFA (\%kJ) & 12 & 3 & 18 & 4 & $6^{*}$ & 5,7 \\
\hline MUFA (\%kJ) & 11 & 2 & 11 & 2 & 0 & $-1,1$ \\
\hline PUFA (\%kJ) & 6 & 1 & 4 & 1 & $-2^{*}$ & $-3,-2$ \\
\hline SAFA (\%TF) & 37 & 5 & 49 & 5 & $12^{*}$ & 10,14 \\
\hline MUFA (\%TF) & 33 & 3 & 29 & 3 & $-4^{*}$ & $-5,-3$ \\
\hline PUFA (\%TF) & 19 & 4 & 11 & 4 & $-8^{*}$ & $-10,-7$ \\
\hline $\mathrm{P}: \mathrm{S}$ ratio & 0.5 & 0.2 & 0.2 & 0.1 & $-0.3^{*}$ & $-0.4,-0.2$ \\
\hline Alcoholł (\%kJ) & 4 & 5 & 4 & 5 & 0 & 0,0 \\
\hline Cholesterol (mg/d) & 237 & 93 & 348 & 133 & $119^{*}$ & 80,157 \\
\hline Butter $(g / d)$ & 3 & 3 & 32 & 23 & $30^{*}$ & 25,36 \\
\hline Margarine (g/d) & 20 & 11 & 1 & 2 & $19^{*}$ & 17,22 \\
\hline
\end{tabular}

SAFA, saturated fat; TF, total fat; P:S, polyunsaturated:saturated.

Mean values were significantly different; ${ }^{\star} P<0.05$.

† Mean difference by regression analysis, adjusted for sex and age.

‡Data were transformed for regression analysis; arithmetic mean presented.

For details of subjects and procedures, see p. 378 of proofs. 
Table 3. Percentage contribution of food groups to total dietary fat intake

(Mean values and standard deviations)

\begin{tabular}{|c|c|c|c|c|}
\hline \multirow[b]{2}{*}{ Food group } & \multicolumn{2}{|c|}{$\begin{array}{l}\text { Margarine } \\
\quad(n 65)\end{array}$} & \multicolumn{2}{|c|}{$\begin{array}{l}\text { Butter } \\
(n 64)\end{array}$} \\
\hline & Mean & SD & Mean & SD \\
\hline Bakery products & $13 \cdot 8$ & $8 \cdot 6$ & $10 \cdot 7$ & 8 \\
\hline Dairy & $16 \cdot 5$ & $8 \cdot 7$ & $43 \cdot 5^{\star \star \star}$ & $15 \cdot 1$ \\
\hline Butter & $2 \cdot 8$ & $3 \cdot 3$ & $25 \cdot 8^{\star \star \star}$ & $12 \cdot 9$ \\
\hline Other & $13 \cdot 7$ & $8 \cdot 3$ & $17 \cdot 7^{\star}$ & 10 \\
\hline Eggs & 1.9 & 2 & $2 \cdot 4$ & $3 \cdot 2$ \\
\hline Fast foods & $4 \cdot 7$ & $7 \cdot 6$ & $5 \cdot 8$ & $8 \cdot 5$ \\
\hline Fats and oils & $25 \cdot 2$ & $10 \cdot 7$ & $5 \cdot 2^{\star \star \star}$ & 5.9 \\
\hline Margarine & $20 \cdot 4$ & $10 \cdot 5$ & $0.5^{\star \star \star}$ & $1 \cdot 6$ \\
\hline Other & $4 \cdot 8$ & $5 \cdot 3$ & $4 \cdot 7$ & $5 \cdot 7$ \\
\hline Meat and meat products & $19 \cdot 6$ & $10 \cdot 9$ & $15 \cdot 0^{\star}$ & $8 \cdot 7$ \\
\hline Nuts & $4 \cdot 1$ & $6 \cdot 2$ & $4 \cdot 4$ & 6 \\
\hline
\end{tabular}

Mean values were significantly different from margarine group, adjusted for age and sex; ${ }^{*} P<0.05,{ }^{\star \star} P<0.01,{ }^{* \star *} P<0.001$

For details of subjects and procedures, see p. 378 of proofs.

predominant 18:1 trans isomer in plasma phospholipid, accounting for $50 \%$ of the total 18:1 trans fatty acid content in butter consumers and $37 \%$ in margarine consumers. Overall, the total trans fatty acid content $(16: 1,18: 1$ and $18: 2$ trans isomers) of plasma phospholipids in butter users was $0.318 \mathrm{~mol} \%$ lower than in margarine users $(P<0.001$ for difference), which was almost entirely explained by the difference in the $18: 1$ trans isomer content $(0 \cdot 306 \mathrm{~mol} \%)$.

Three 18:2 isomers containing a trans double bond were identified in plasma phospholipids. Concentrations of both the $18: 2 \mathrm{ct} 3$ and $18: 2 \mathrm{ct} 4$ isomers were higher in the plasma phospholipids of margarine than butter users, although the magnitude of the difference was small (adjusted mean differences $0.010 \mathrm{~mol} \%, P<0.001$ and $0.021 \mathrm{~mol} \%, P=0.003$; respectively). In contrast, the $18: 2 \mathrm{ct} 2$ isomer level was higher in the phospholipids of butter compared with margarine users $(0.033 \mathrm{~mol} \%$ v. $0.023 \mathrm{~mol} \%, P<0.001)$. The sum of all $18: 2$ ct isomers was no different between the two groups.

The relationship between plasma phospholipid 18:1 and 18:2 trans isomers, and the percentages of total fat from butter (in butter users only) and margarine (in margarine users only) are shown in Fig. 1. Levels of all 18:1 trans positional isomers in plasma phospholipid were positively related to the percentage of dietary fat from margarine in margarine users. Margarine intake was more strongly associated with the phospholipids $18: 1 n$-6t, $18: 1 n-8 \mathrm{t}$ and $18: 1 n$ $12 / n$-9t isomers $(r 0.57-0.63, P<0.001)$ than with $18: 1 n-7 \mathrm{t}$ ( $r$ 0.30, $P=0.016$ ). There was no correlation in butter users between the percentage of fat from butter and the phospholipid $18: 1$ trans positional isomers $(r 0 \cdot 13-0 \cdot 24, P=0 \cdot 290-0 \cdot 058)$. Phospholipid $18: 2 \mathrm{ct} 2$ was positively associated with the percentage of dietary fat from butter in butter users $(r 0.41$, $P=0.001)$ but unrelated to the percentage of dietary fat from margarine in margarine users $(r 0.05, P=0.714)$.

Aside from butter and margarine, fat from ruminant meat, meat and meat products, bakery products, vegetable oils (some of which could be 'brush hydrogenated'), fast foods and dairy products other than butter are potential dietary sources of trans fatty acids. The percentage of fat from these food groups was not significantly related to $18: 1$ or $18: 2$ trans isomers in the plasma phospholipids of margarine or butter users after controlling for margarine and butter intake, respectively (data not shown).

\section{Discussion}

Home use of margarines made with partially hydrogenated vegetables oils is a source of trans fatty acids, but it is difficult to determine the relative importance of this food choice in determining total intake because, in the absence of a food composition database containing trans fatty acid data, the amount of trans fatty acid from other food sources, such as manufactured and institutional foods, is difficult to quantify.

Table 4. Plasma phospholipid cis fatty acid composition in butter and margarine users (Values in mol\% and standard deviations)

\begin{tabular}{|c|c|c|c|c|c|c|}
\hline \multirow[b]{2}{*}{ Fatty acid } & \multicolumn{2}{|c|}{ Margarine (n 65) } & \multicolumn{2}{|c|}{ Butter (n 64) } & \multicolumn{2}{|c|}{ Difference† } \\
\hline & Mean & SD & Mean & SD & Mean & $95 \% \mathrm{Cl}$ \\
\hline $14: 0$ & 0.487 & 0.116 & 0.623 & 0.118 & $0.144^{*}$ & $0.103,0.184$ \\
\hline $15: 0$ & 0.262 & 0.063 & 0.348 & 0.061 & $0.088^{*}$ & $0.066,0.110$ \\
\hline $16: 0$ & 30.644 & 1.607 & $31 \cdot 105$ & 1.36 & 0.484 & $-0.048,1.016$ \\
\hline $16: 1 n-7$ & 0.646 & 0.191 & 0.761 & 0.272 & $0.115^{\star}$ & $0.033,0.198$ \\
\hline $18: 0$ & $13 \cdot 114$ & $1 \cdot 216$ & $12 \cdot 630$ & $1 \cdot 132$ & $-0.442^{*}$ & $-0.863,-0.021$ \\
\hline $18: 1 n-9$ & $7 \cdot 812$ & $1 \cdot 116$ & 8.912 & 1.334 & $1 \cdot 144^{*}$ & $0.704,1.584$ \\
\hline $18: 2 n-6$ & $19 \cdot 282$ & 2.533 & 17.933 & 2.609 & $-1.502^{*}$ & $-2.403,-0.600$ \\
\hline $18: 3 n-3$ & 0.185 & 0.078 & 0.276 & 0.103 & $0.095^{\star}$ & $0.063,0.128$ \\
\hline $20: 3 n-6$ & $2 \cdot 616$ & 0.512 & 2.531 & 0.418 & -0.117 & $-0.282,0.048$ \\
\hline $20: 4 n-6$ & $7 \cdot 438$ & $1 \cdot 318$ & 6.562 & 1.295 & $-0.966^{\star}$ & $-1.429,-0.504$ \\
\hline $20: 5 n-3$ & 0.859 & 0.425 & $1 \cdot 244$ & 0.361 & $0.407^{*}$ & $0.275,0.538$ \\
\hline $22: 0$ & 1.556 & 0.239 & 1.455 & 0.252 & $-0.098^{*}$ & $-0.185,-0.011$ \\
\hline $22: 5 n-3$ & 0.846 & 0.180 & 0.973 & 0.175 & $0.149^{\star}$ & $0.095,0.203$ \\
\hline $22: 6 n-3$ & $2 \cdot 338$ & 0.628 & $2 \cdot 359$ & 0.571 & 0.038 & $-0.173,0.249$ \\
\hline $24: 0$ & 1.338 & 0.191 & $1 \cdot 301$ & 0.204 & -0.034 & $-0.102,0.033$ \\
\hline $24: 1 n-9$ & 1.629 & 0.321 & 1.765 & 0.268 & $0.120^{*}$ & $0.018,0.222$ \\
\hline
\end{tabular}

Mean values were significantly different; ${ }^{*} P<0.05$

$\dagger$ Mean difference by regression analysis, adjusted for sex and age.

For details of subjects and procedures, see p. 378 of proofs. 
Table 5. Correlation coefficients for the association between plasma phospholipid fatty acids and fat intake

\begin{tabular}{lcccc}
\hline Type of fat & Unit of fat & $14: 0 \dagger$ & $15: 0 \dagger$ & $16: 0$ \\
\hline Saturated fat & g/d & 0.34 & 0.42 & $-0.06(P<0.476)$ \\
& \% energy & 0.45 & 0.55 & $-0.03(P<0.718)$ \\
Dairy fat & \% total fat & 0.56 & 0.59 & $0.15(P<0.100)$ \\
& g/d & 0.42 & 0.52 & $-0.03(P<0.725)$ \\
& \% energy & 0.49 & 0.60 & $0.02(P<0.842)$ \\
& \% total fat & 0.54 & 0.62 & $0.09(P<0.287)$ \\
\hline
\end{tabular}

†All correlation coefficients for $14: 0$ and $15: 0$ with fat type are $P<0.001$.

For details of subjects and procedures, see p. 378 of proofs.

We have shown, using plasma phospholipid trans fatty acid composition as a biomarker of dietary intake, that the consumption of margarine made with partially hydrogenated vegetable oil is an important determinant of trans fatty exposure in New Zealand. The diets of participants in the present study were similar in fat content to those reported in the National Nutrition Survey (Skeaff et al. 2001), suggesting that our results are applicable generally to adult New Zealanders.

The position of the carbon-carbon double bond in the $18: 1$ trans isomers of partially hydrogenated vegetable oils tends to follow a normal distribution along the molecule, with a predominance around the centre ( $n-6$ to $n-12$; Marchand, 1982; Molkentin \& Precht, 1996), whereas in butter there is a distinct predominance of the 18:1n-7 trans isomer (Precht \& Molkentin, 1995; Wolff, 1995). The higher proportion of $18: 1 n-12 / 9 \mathrm{t}, 18: 1 n-8 \mathrm{t}$ and $18: 1 n-6 \mathrm{t}$ isomers in the plasma phospholipid of margarine consumers is consistent with this difference in the trans composition of margarine. Furthermore, margarine consumption explained almost $40 \%$ of the variation in the plasma phospholipid composition of these isomers, whereas butter consumption was not associated with these isomers. Had the majority of partially hydrogenated oils in the New Zealand diet come from food sources other than margarine, we would have expected to find no or only weak associations between margarine intake and trans fatty acid status. When the study was conducted, the average trans fatty content of
New Zealand margarines was between 5.9 and 16.0 weight $\%$ of total fatty acids (Ball et al. 1993; Lake et al. 1996); hard or stick margarines with much higher trans composition as well as 'zero trans' spreads were not available to consumers. It is possible that in countries where the use of partially hydrogenated vegetable oils in manufactured and institutional foods is higher, the consumption of margarines containing partially hydrogenated fats will be a less important determinant of trans fatty acid status.

There was no difference between the butter and margarine groups in the $18: 1 n-7 \mathrm{t}$ composition of plasma phospholipid, nor was there an association between margarine or butter intake and this isomer in plasma phospholipids. This suggests that the intake of $18: 1 n-7 \mathrm{t}$ was similar in butter and margarine consumers, and that home use of butter or margarine was not a major source of this isomer relative to other foods. $18: 1 \mathrm{n}-7 \mathrm{t}$ was the trans isomer present in the highest proportion in plasma phospholipid, but we found no correlation between it and the intake of fat from any of the food groups. The most likely explanation is that dairy and other ruminant fats are commonly used in most manufactured foods and intake is evenly spread across the food groups. There is some evidence that $18: 1 n-7 \mathrm{t}(\Delta 11)$ can be desaturated in essential fatty aciddeficient animals to $18: 2 \Delta^{9-c i s} \Delta^{11-t r a n s}$ (Mahfouz et al. 1980; Pollard et al. 1980); if this occurred in man, it would attenuate the association between the dietary intake and plasma composition of this fatty acid; however, using ${ }^{2} \mathrm{H}$-labelled 18:1i-7t, Emkem et al. (1986) found no evidence of bioconversion.

Consistent with results reported by others (Wolk et al. 1998; Smedman et al. 1999) we confirm that plasma phospholipid 15:0 and 14:0 are good biomarkers of dairy fat intake, with 15:0 appearing to be marginally better.

Butter was not a determinant of trans MUFA but was correlated weakly with $18: 2 \mathrm{ct} 2$ in plasma phospholipid. This isomer is most probably one of the group of isomers comprising conjugated linoleic acid. Conjugated linoleic acid is consumed in small quantities, but its higher content in butter (Jensen, 2002) relative to other foods is consistent with the association we found.

Table 6. Positional and geometrical fatty acid isomers of plasma phospholipids (Values in mol\% and standard deviations)

\begin{tabular}{|c|c|c|c|c|c|c|}
\hline \multirow[b]{2}{*}{ Fatty acid } & \multicolumn{2}{|c|}{ Margarine $(n 65)$} & \multicolumn{2}{|c|}{ Butter ( $n$ 64) } & \multicolumn{2}{|c|}{ Difference $†$} \\
\hline & Mean & SD & Mean & SD & Mean & $95 \% \mathrm{Cl}$ \\
\hline $16: 1 n-7 t$ & 0.063 & 0.031 & 0.069 & 0.023 & 0.007 & $-0.003,0.017$ \\
\hline $18: 1 n-12 / 9 t$ & 0.374 & $0 \cdot 120$ & 0.230 & 0.036 & -0.138 & $-0.169,-0.106$ \\
\hline $18: 1 n-8 t$ & 0.145 & 0.043 & 0.091 & 0.015 & $-0.052^{*}$ & $-0.063,-0.040$ \\
\hline $18: 1 n-7 t$ & 0.455 & 0.129 & 0.456 & 0.085 & 0.003 & $-0.036,0.043$ \\
\hline $18: 1 n-6 t$ & 0.266 & $0 \cdot 102$ & 0.140 & 0.033 & $-0.120^{*}$ & $-0.148,-0.093$ \\
\hline Sum 18: 1t isomers & $1 \cdot 240$ & 0.344 & 0.918 & 0.130 & $-0.306^{*}$ & $-0.399,-0.213$ \\
\hline $18: 2 \operatorname{ct} 1 \S$ & 0.210 & 0.029 & 0.209 & 0.024 & 0.001 & $-0.008,0.011$ \\
\hline $18: 2 \operatorname{ct} 2 \S$ & 0.023 & 0.009 & 0.033 & 0.014 & $0.011^{*}$ & $0.007,0.015$ \\
\hline $18: 2 \operatorname{ct} 3 \S$ & 0.038 & 0.015 & 0.028 & 0.009 & $-0.010^{\star}$ & $-0.015,-0.006$ \\
\hline $18: 2 \operatorname{ct} 4 \S$ & 0.110 & 0.042 & 0.088 & 0.031 & $-0.021^{\star}$ & $-0.034,-0.007$ \\
\hline Sum $\mathrm{C} 18: 2 \mathrm{t}$ isomers & 0.381 & 0.065 & 0.358 & 0.053 & -0.019 & $-0.040,0.003$ \\
\hline Sum trans isomers & 1.684 & 0.387 & 1.345 & 0.161 & $-0.318^{*}$ & $-0.423,-0.212$ \\
\hline
\end{tabular}

Mean values were significantly different; ${ }^{\star} P<0.05$.

$\dagger$ Mean difference by regression analysis, adjusted for sex and age.

$\ddagger$ May include the $18: 1 n-12$ to $n$ - 12 to $n-10$ cis isomers.

$\S$ Position of double bonds unknown. 

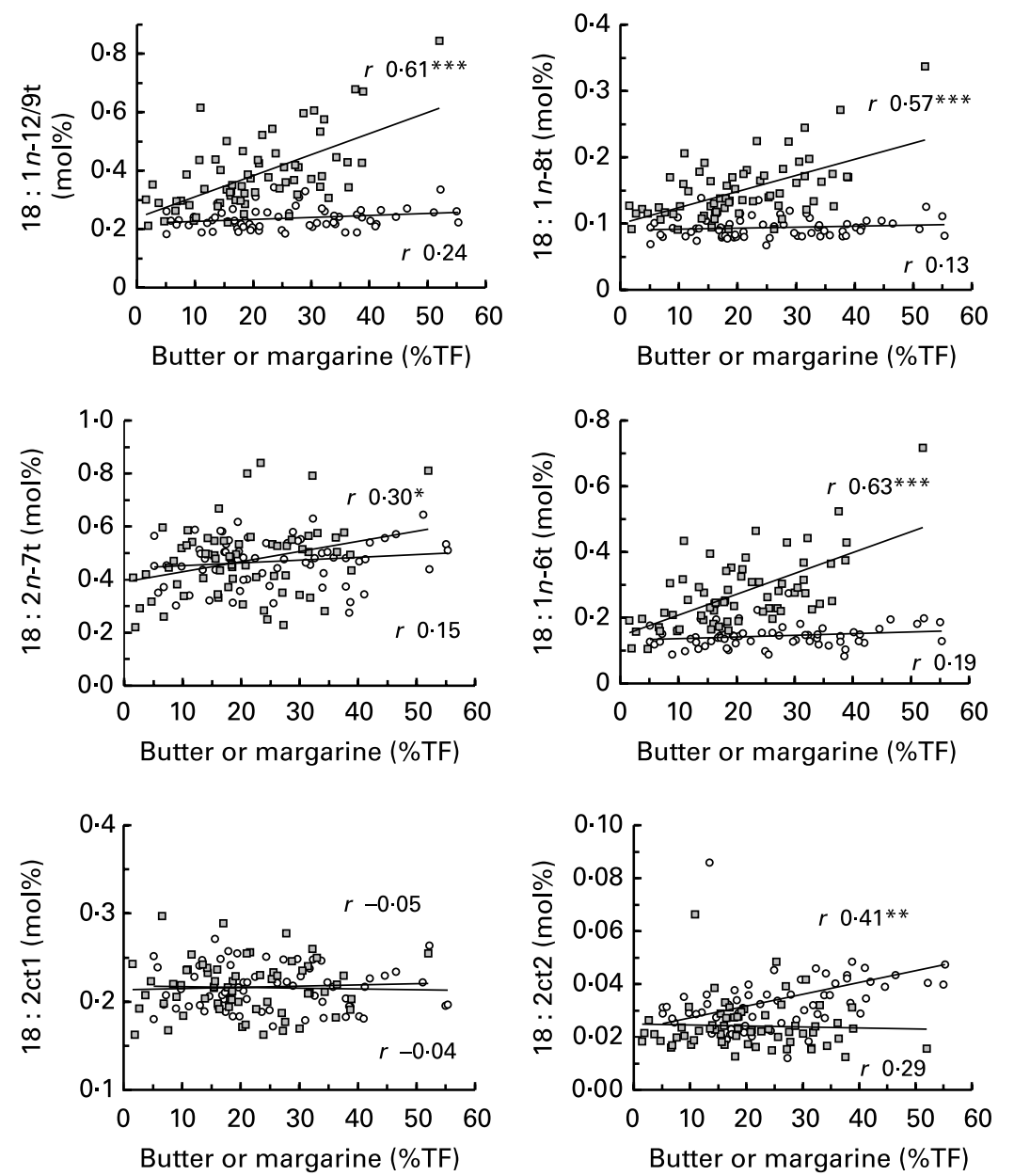

Fig. 1. Relationship between margarine or butter intake and trans isomeric composition of plasma phospholipid. $\square$, margarine consumers; $O$, represent butter consumers. \%TF, percentage total fat. ${ }^{\star} P<0.05,{ }^{* \star} P<0.01$, ${ }^{\star \star *} P<0.001$.

The total trans fatty acid content in the plasma phospholipids of butter users in the present study was $1.345 \mathrm{~mol} \%$. This is remarkably similar to findings from a controlled feeding trial by Vidgren et al. (1998), in which the total trans fatty acid content of plasma phospholipids from participants consuming a diet with $1.4 \% \mathrm{~kJ}$ from trans fatty acids was $1.25 \mathrm{~mol} \%$; the similarity is likely to be even closer because $16: 1 n-7 \mathrm{t}$, the value for which was $0.07 \mathrm{~mol} \%$ in our study, was not measured by Vidgren et al. In that study, the increase in the total trans fatty acid composition of plasma phospholipid when changing to a higher trans fatty acid diet $(5.5 \% \mathrm{~kJ})$ was directly proportion to the increase in dietary trans intake. Thus, on the basis of the similarity in the trans fatty acid content of plasma phospholipids between Vidgren et al.'s study and ours, butter users in our study were probably consuming around $1.4 \% \mathrm{~kJ}(4 \mathrm{~g} / \mathrm{d})$ as trans fatty acids. We estimated from the dietary records that dairy fat $(43.5 \%$ total fat intake; Table 3) contributed $2.6 \mathrm{~g} / \mathrm{d}$ of trans fat - assuming a trans fatty acid composition of dairy fat of 5.9 weight $\%$ (Lake et al. 1996). Therefore, in the butter group, the remainder of the diet probably contained no more than $1.4 \mathrm{~g} / \mathrm{d}$ trans fatty acids. The proportion of this trans fat derived from animal or plant sources is difficult to estimate.

Obviously, the easiest way to reduce trans fatty acid intake is to avoid butter or margarines made with partially hydrogenated plant oils. However, using a fat for spreading and in home baking and cooking is a habit not easily changed in many countries. For this reason, we have previously shown that, in people with a slightly raised plasma cholesterol level, a low-fat diet in which butter is replaced with a polyunsaturated and monounsaturated-rich margarine, despite the latter containing $13 \%$ trans fatty acids, lowers plasma LDL-cholesterol (Chisholm et al. 1996). The relevance of this finding was that low-trans fatty acid margarines, at the time the only ones available in New Zealand, were appropriate for cholesterol-lowering diets despite containing more trans fatty acids than butter. However, our current results indicate that if there are untoward effects of trans fatty acids, other than on plasma lipoproteins, it would be preferable to use a margarine with no trans fatty acids. These margarines are now available, although they were not at the time we conducted the study.

We have used a biological marker of trans fatty acid intake to show that the consumption of trans fatty acid-containing margarines is a major determinant of trans fatty status. This result provides persuasive - albeit indirect - evidence that the use of partially hydrogenated vegetable oils in other manufactured foods at the time of our study was not high in New Zealand. A similar biomarker approach may be useful in other countries where the amount of partially hydrogenated vegetable oils in manufactured foods is unknown. 


\section{Acknowledgements}

The authors thank Margaret Waldron for her clinical assistance and the participants. Funding came from a University of Otago Research Grant.

\section{References}

Ascherio A, Rimm EB, Giovannucci EL, Spiegelman D, Stampfer M \& Willett WC (1996) Dietary fat and risk of coronary heart disease in men: cohort follow up study in the United States. BMJ 313, 84-90.

Ball MJ, Hackett D \& Duncan A (1993) Trans fatty acid content of margarines, oils and blended spreads available in New Zealand. Asia Pacif J Clin Nutr 2, 165-169.

Beaton GH, Milner J, Corey P, et al. (1979) Sources of variance in 24-hour dietary recall data: implications for nutrition study design and interpretation. Am J Clin Nutr 32, 2546-2559.

Bingham S (1987) The dietary assessment of individuals; methods, accuracy, new techniques and recommendations. Nutr Abstr Rev 57, 705-742.

Bingham SA, Gill C, Welch A, Day K, Cassidy A, Khaw KT, Sneyd MJ, Key TJ, Roe L \& Day NE (1994) Comparison of dietary assessment methods in nutritional epidemiology: weighed records v. $24 \mathrm{~h}$ recalls, food-frequency questionnaires and estimated-diet records. Br J Nutr 72, 619-643.

Burlingame B, Milligan G, Apimerika D \& Arthur J (1993) The New Zealand Food Composition Tables. Palmerston North, New Zealand: New Zealand Institute for Crop and Food Research.

Chisholm A, Mann J, Sutherland W, Duncan A, Skeaff M \& Frampton C (1996) Effect on lipoprotein profile of replacing butter with margarine in a low fat diet: randomised crossover study with hypercholesterolaemic subjects. BMJ 312, 931-934.

Elias SL \& Innis SM (2002) Bakery foods are the major dietary source of trans-fatty acids among pregnant women with diets providing 30 percent energy from fat. J Am Diet Assoc 102, 46-51.

Emken EA, Rohwedder WK, Adlof RO, DeJarlais WJ \& Gulley RM (1986) Absorption and distribution of deuterium-labeled trans- and cis-11-octadecenoic acid in human plasma and lipoprotein lipids. Lipids 21, 589-595.

Firestone D \& Sheppard A (1992) Determination of trans fatty acids. In Advances in Lipid Methodology, pp. 273-322 [WA Christie, editor]. Bridgwater, UK: Oily Press.

Goldberg GR, Black AE, Jebb SA, Cole TJ, Murgatroyd PR, Coward WA \& Prentice AM (1991) Critical evaluation of energy intake data using fundamental principles of energy physiology. 1. Derivation of cut-off limits to identify under-recording. Eur $J$ Clin Nutr 45, 569-581.

Holub BJ \& Skeaff CM (1987) Nutritional regulation of cellular phosphatidylinositol. Methods Enzymol 141, 234-244.

Hu FB, Stampfer MJ, Manson JE, Rimm E, Colditz GA, Rosner BA, Hennekens CH \& Willett WC (1997) Dietary fat intake and the risk of coronary heart disease in women. $N$ Eng J Med 337, 1491-1499.

Hudgins LC, Hirsch J \& Emken EA (1991) Correlation of isomeric fatty acids in human adipose tissue with clinical risk factors for cardiovascular disease. Am J Clin Nutr 53, 474-482.

Innis SM, Green TJ \& Halsey TK (1999) Variability in the trans fatty acid content of foods within a food category: implications for estimation of dietary trans fatty acid intakes. J Am Coll Nutr 18, $255-260$.

Jensen RG (2002) The composition of bovine milk lipids: January 1995 to December 2000. J Dairy Sci 85, 295-350.

Lake R, Thomson B, Devane G \& Scholes P (1996) Trans fatty acid content of selected New Zealand foods. J Food Compost Anal 9, $365-374$.
Lichtenstein AH, Ausman LM, Jalbert SM \& Schaefer EJ (1999) Effects of different forms of dietary hydrogenated fats on serum lipoprotein cholesterol levels. $N$ Engl J Med 340, 1933-1940.

Lichtenstein AH, Erkkila AT, Lamarche B, Schwab US, Jalbert SM \& Ausman LM (2003) Influence of hydrogenated fat and butter on CVD risk factors: remnant-like particles, glucose and insulin, blood pressure and C-reactive protein. Atherosclerosis $\mathbf{1 7 1}$ 97-107.

Mahfouz MM, Valicenti AJ \& Holman RT (1980) Desaturation of isomeric trans-octadecenoic acids by rat liver microsomes. Biochim Biophys Acta 618, 1-12.

Marchand C (1982) Positional isomers of trans-octadecenoic acids in margarines. Can Inst Food Sci Technol J 15, 196-199.

Mensink RP \& Katan MB (1990) Effect of dietary trans fatty acids on high-density and low-density lipoprotein cholesterol levels in healthy subjects. $N$ Eng $J$ Med 323, 439-445.

Molkentin J \& Precht D (1996) Isomeric distribution and rapid determination of trans-octadecenoic acids in German brands of partially hydrogenated edible fats. Nahrung 6, 297-304.

Parodi PW (1976) Distribution of isomeric octadecenoic fatty acids in milk fat. J Dairy Sci 59, 1870-1873.

Pietinen P, Ascherio A, Korhonen P, Hartman AM, Willett WC, Albanes D \& Virtamo J (1997) Intake of fatty acids and risk of coronary heart disease in a cohort of Finnish men. The Alpha-Tocopherol, Beta-Carotene Cancer Prevention Study. Am J Epidemiol 145, 876-887.

Pollard MR, Gunstone FD, James AT \& Morris LJ (1980) Desaturation of positional and geometric isomers of monoenoic fatty acids by microsomal preparations from rat liver. Lipids 15, 306-314.

Precht D \& Molkentin J (1995) Trans fatty acids: implications for health, analytical methods, incidence in edible fats and intake (a review). Nahrung 39, 343-374.

Ratnayake W \& Beare-Rogers J (1990) Problems of analysing C18 cis- and trans-fatty acids of margarine on the SP-2340 capillary column. J Chromatogr Sci 28, 633-639.

Ratnayake W \& Pelletier G (1992) Positional and geometrical isomers of linoleic acid in partially hydrogenated oils. J Am Oil Chem Soc 69, 95-105.

Seppanen-Laakso T, Laakso I, Backlund P, Vanhanen H \& Viikari J (1996) Elaidic and trans-vaccenic acids in plasma phospholipids as indicators of dietary intake of 18:1 trans-fatty acids. J Chromatogr B Biomed Appl 687, 371-378.

Skeaff CM, Mann JI, McKenzie J, Wilson NC \& Russell DG (2001) Declining levels of total serum cholesterol in adult New Zealanders. N Z Med J 114, 131-134.

Slover HT, Thompson RHJ, Davis CS \& Merola GV (1985) Lipids in margarines and margarine-like foods. J Am Oil Chem Soc 62, $775-786$.

Smedman AE, Gustafsson IB, Berglund LG \& Vessby BO (1999) Pentadecanoic acid in serum as a marker for intake of milk fat: relations between intake of milk fat and metabolic risk factors. Am J Clin Nutr 69, 22-29.

van de Vijver LP, van Poppel G, van Houwelingen A, Kruyssen DA \& Hornstra G (1996) Trans unsaturated fatty acids in plasma phospholipids and coronary heart disease: a case-control study. Atherosclerosis 126, 155-161.

Vidgren HM, Louheranta AM, Agren JJ, Schwab US \& Uusitupa MI (1998) Divergent incorporation of dietary trans fatty acids in different serum lipid fractions. Lipids 33, 955-962.

Wolff $\mathrm{R}$ (1995) Content and distribution of trans-18:1 acids in ruminant milk and meat fats. Their importance in European diets and their effect on human milk. J Am Oil Chem Soc 72, $259-272$.

Wolk A, Vessby B, Ljung H \& Barrefors P (1998) Evaluation of a biological marker of dairy fat intake. Am J Clin Nutr 68, 291-295. 